\section{Case 1}

A single female clerk aged 23 years was admitted on November 30,1949 , with a seven-days history of pain in her abdomen, unrelieved by any form of therapy and associated with vomiting. At the age of 18 she had dry pleurisy; there was no family history of tuberculosis.

On examination the patient was seen to be well nourished; palpable glands were present in the neck, she had a cough, and her temperature was $101.6^{\circ} \mathrm{F}$. $\left(38.7^{\circ} \mathrm{C}\right.$.). The lungs showed some degree of dullness on the right side, with diminished air entry and vocal resonance. The abdomen was slightly distended, and there was diffuse tenderness with signs of free fluid in the abdominal cavity. A radiograph of the chest disclosed an effusion in the right pleural cavity. Her sputum did not contain tubercle bacilli. The erythrocyte sedimentation rate after one hour was $65 \mathrm{~mm}$. A blood count showed: $\mathrm{Hb}, 80 \%$; red cells, $4,900,000$ per c.mm.; white cells, 7,000 per c.mm. A film revealed occasional hypochromic cells. Tuberculous peritonitis was diagnosed, and laparotomy performed.

On exploring the abdomen the peritoneum was nearly $\frac{1}{4}$ in. $(0.6 \mathrm{~cm}$.) thick, and this confirmed the diagnosis of tuberculous peritonitis. The abdominal cavity contained a large quantity of straw-coloured fluid, several pints being aspirated from the pelvis. The intestines were matted together into one homogeneous mass and many tubercles were seen on the peritoneum and the bowel wall. The pelvic organs showed typical tuberculous infection, both tubes being densely adherent to the brim of the pelvis.

It was suggested that the patient might be treated with streptomycin. The fluid was sent to the laboratory for culture, which later showed a growth of tubercle bacilli.

Treatment consisted of $1 \mathrm{~g}$. of streptomycin daily, given in four equal doses. After 12 days, P.A.S., 12 g. daily, was added to prevent streptomycin resistance. A few days later the temperature began to subside, and on examination the lung fields were clear. The patient was transferred to Leasowe Open-air Hospital, where treatment was continued ; a complete course of $88 \mathrm{~g}$. of streptomycin was given.

After six months the E.S.R. was only $3 \mathrm{~mm}$. in one hour; her weight had increased by $8 \mathrm{lb}$. $(3.6 \mathrm{~kg}$.), and her general condition improved considerably. She continued to attend the out-patient department at regular intervals for further supervision.

\section{Case 2}

A housewife aged 46 was admitted on January 11,1950 with a history of pain in her abdomen radiating towards the back; the pain was not related to food. There was no nausea or vomiting, and her temperature was $104^{\circ} \mathrm{F}$. $\left(40^{\circ}\right.$ C. $)$.

On examination the patient was very flushed; auscultation of the lungs revealed scattered crepitations and rhonchi ; there was dullness at the right base with diminished air entry. A radiograph of the chest revealed a right-sided pleural effusion. A blood count at this time showed: $\mathrm{Hb}, 70 \%$; red cells, 4,800,000; white cells, 7,600 (polymorphs $80 \%$, lymphocytes $17 \%$, hyalines $3 \%$ ). A film showed marked anisocytosis with many hypochromic cells. The E.S.R. was $76 \mathrm{~mm}$. in one hour. The abdomen showed some degree of distension combined with diffuse tenderness. A mass could be felt in the lower part of the abdomen on the right side, and evidence of free fluid was present. It was decided to perform a laparotomy to confirm the diagnosis, which clinically was suggestive of tuberculosis.

The abdomen was opened through a subumbilical midline incision and a large quantity of fluid escaped. The appearances were typical of acute tuberculous peritonitis, the peritoneum, bowel, and pelvic organs all being studded with minute tubercles. About a gallon (4.5 litres) of fluid was present in the pelvis; the omentum was rolled up and thickened, particularly in the neighbourhood of the right iliac fossa, and this thickening was the cause of the mass described above. The abdomen was closed in the usual way. The fluid, unlike that in Case 1 , was sterile on culture.

Streptomycin treatment, $1 \mathrm{~g}$. daily given in four equal doses, combined with 12 g. of P.A.S., was begun immediately. The patient's general condition improved rapidly, her temperature subsided, and the physical signs in the lungs and pleura became normal affer 14 days. At this stage she was transferred to Leasowe Open-air Hospital. The E.S.R. dropped to $15 \mathrm{~mm}$. in one hour, the patient put on weight, and her general condition improved considerably. She was kept under further observation and attended the out-patient department. The total dosage of streptomycin given in this case was about $80 \mathrm{~g}$.

It is interesting to note the similarity between these cases. Both patients had considerable pyrexia on admission, and an effusion was present in the pleural cavity. It is, of course, impossible to reach a conclusion at the present stage, and further prolonged observation is necessary before the results of this treatment can be assessed.

We are indebted to Dr. J. K. Cameron, medical superintendent, Leasowe Open-air Hospital, for his assistance in treating these cases, and to Dr. L. Ashcroft, pathologist, St. Catherine's Hospital, for the bacteriological findings.

R. A. Grant, F.R.C.S.Ed., Surgeon-Superintendent.

A. GRunberg, M.D., Physician.

J. Lindsay Blair, M.D., Medical Registrar.

St. Catherine's Hospital, Birkenhead.

\section{BIBLIOGRAPHY}

Brown, T. M., and Wichelhausen, R. H. (1949). Amer. J. Med. $6,506$.

Gaafar, M., and El Badry, A. (1949). J. R. Egypt. med. Ass., 32 483 .

Mileoskaya, U. L. (1949). Klin. Med., Mosk., 27, 90. (In Russian.)

Pasqualini, R. Q., et al. (1949). Prensa méd. argent., 36, 352. Ravina, A., and Rondy, A. (1948). Bull. Soc. méd. Hôp. Paris, 64, 1117 .

\section{Conception in Spite of Extreme Oligozoospermia}

Three case histories are presented to illustrate the point that a finding of extreme oligozoospermia does not necessarily mean a hopeless prognosis. After treatment natural conception occurred in each instance. Although with the degree of oligozoospermia present this is very rare, it does suggest that, at least with young couples, a grave but guarded prognosis is more appropriate, and that treatment should be attempted.

For purposes of comparison we may mention that at this clinic the minimum standard of fecundity of semen (not ordinarily necessitating treatment) requires a volume of not less than $2 \mathrm{ml}$, a density of not less than $30,000,000$ spermatozoa per $\mathrm{ml} ., 50 \%$ motility after two hours at $37^{\circ} \mathrm{C}$., with not more than $25 \%$ abnormal headforms, a low content of testicular cells and polymorphs, and absence of agglutination of sperms.

\section{Case 1}

This couple were referred on account of infertility. The husband was 26 and an only child; wife 25 ; married six years; intercourse never satisfactory. The husband worked long hours as a chef in hot and airless surroundings. He had no history of illness, except dental caries. He looked pallid and ill, and had extensive acne of the face, neck, and back. The right testicle was undescended; the left testicle had descended and was of normal size. 
First Semen Test.-After one week's abstinence. Volume, $5 \mathrm{ml}$; occasional spermatozoa, immotile after two hours, and with variable but generally bad differentiation; many polymorphs.

He was advised to take a different job with shorter hours and to limit his smoking to 10 cigarettes a day. $\mathrm{He}$ was given a course of sulphonamides, followed by injections of iron and arsenic for six weeks, and also $B$ vitamins and a liver preparation by mouth.

Second Semen Test.-Two months later: after one week's abstinence. Large volume $(6 \mathrm{ml}$ ) ; many granular bodies ; occasional non-motile spermatozoa in fresh specimen; occasional spermatocytes; no polymorphs.

After continuation of the previous treatment the acne disappeared, he looked much better, put on weight, and lost his fatigue.

Third Semen Test.-Two months later: after one week's abstinence. Very large volume $(8 \mathrm{ml}$.) ; occasional motile sperms in fresh specimen, which were still motile after five hours at room temperature; no cells.

He was then treated for four weeks with serum gonadotrophin 500 units three times a week. His wife was examined at this stage and found to have a severely ulcerated cervix covered with purulent Nabothian follicles from which a viridans-type streptococcus was isolated. The cervix was cauterized, sulphonamides were given by mouth, and penicillin intracervically and systemically. She responded well to treatment, and no other abnormalities or infertility factors were found.

A post-coital test after treatment of the wife showed sperms in the vagina, but none in the cervical canal.

Fourth Semen Test.-Five months after the third: after 12 days' abstinence. Volume, $3.4 \mathrm{ml}$.; 0.025 million sperms per ml. ; sperms immotile after two and three-quarter hours.

The couple were advised to continue the general dietary measures and to practise planned intercourse; the latter was now much more satisfactory. Pregnancy occurred 18 months after the start of treatment of the husband and proceeded normally until the 12th week, when spontaneous abortion took place. Couple advised to try again ; a second conception occurred 15 weeks after the miscarriage, but again miscarriage took place-at six weeks (time of writing).

\section{Case 2}

Advice was sought on account of infertility. The husband was 29; wife 22; married two years; intercourse satisfactory. Seven years prior to marriage the husband was treated by $x$ rays for two months on account of ankylosing spondylitis; he was left with one hip fixed. He also had a history of chronic sinusitis, dysentery, and dengue fever, with severe debility while a prisoner of war in Java. $\mathrm{He}$ was now working in an office and appeared pale and underweight; he had severe nasal catarrh, and inquiries showed that his diet was deficient in protein.

First Semen Test.-After six days' abstinence. Volume, $4 \mathrm{ml}$; occasional well-differentiated sperms, which were motile after three hours; no cells.

Testicular Biopsy.-(One month later.) This showed islands of tubules with evidence of spermatogenesis surrounded by shrunken tubules containing only an undifferentiated syncytium.

The husband was told how to supplement his diet, and was given a liver preparation and vitamins $A$ and $D$ by mouth, and also a full course of iron and arsenic. Conception occurred three months after the beginning of his treatment. Healthy boy, $7 \mathrm{lb} .8 \mathrm{oz}$. $(3.4 \mathrm{~kg}$.), born. Progressing well.

\section{Case 3}

This couple was referred on account of infertility. The husband was 31 ; wife 33 ; married three and a half years ; intercourse satisfactory, but infrequent. It was the wife's second marriage, and she had one child by her first husband. Her present husband had been operated upon in youth for undescended testicles, with reasonably good results, and, though the scrotum and penis were small, the testicles were of normal size. He was working as an electrical engineer, and complained of decreasing libido; otherwise he was well, and he had no history of relevant illness. Two semen tests had been carried out before reference to us, and the sperm counts were stated to have been one million per ml. on the first occasion and seven millions per $\mathrm{ml}$. three years later.

First Semen Test.-After four days' abstinence. Volume, $4.7 \mathrm{ml}$.; 0.88 million sperms per ml.; approximately $62 \%$ abnormal forms; $36 \%$ active after one and three-quarter hours at $37^{\circ}$ C. ; $32 \%$ active after three and three-quarter hours at $37^{\circ}$ C. (high viability); a few leucocytes present.

The husband was given a $200-\mathrm{mg}$. testosterone implant (Mr. G. Quist), with the result that his libido improved.

Second Semen Test.-Three months later: after 24 hours' abstinence. Volume, $2.1 \mathrm{ml}$. ; 0.72 .5 million sperms per $\mathrm{ml}$.; $80 \%$ abnormal forms ; $17 \%$ active after three and threequarter hours at $37^{\circ} \mathrm{C}$.

Third Semen Test.-One month later: after four days' abstinence. Volume, $4.2 \mathrm{ml}$.; 0.78 million sperms per $\mathrm{ml}$.; $60 \%$ abnormal forms; $7.5 \%$ active after two hours; $5 \%$ active after four hours at $37^{\circ} \mathrm{C}$.

During this period the wife had routine fertility tests, and nothing was found wrong with her. Pregnancy occurred three months after the start of the husband's treatment, and the pregnancy is proceeding satisfactorily at the time of writing, now being just over the four months without, so far, any threat of miscarriage.

Although we have had cases under our care in which the sperm counts of the husband showed remarkable variations in a short space of time, in these three cases it is unlikely that the counts varied much during the period of observation. Conception in each case took place naturally in spite of the exceptionally low counts recorded. It will be noted, however, that the semen volume was in each case rather above average, and this may have had some compensatory effect. Again, although some degree of spontaneous recovery might have been expected in Case 2, there seems little doubt that treatment in all three cases accelerated the achievement of pregnancy. It will be recognized that restoration, where necessary, of the wife's fecundity is essential (cf. Case 1). Also, our knowledge of the patients concerned and their circumstances virtually excludes the factor of deception.

MARgaret MoOre White, M.D., F.R.C.S., M.R.C.O.G.

MARY BARTON, M.B., B.S., Fertility Department, Royal Free Hospital.

The Ministry of Health is now setting up fourteen committees to look after the training of nurses, one for each of the fourteen regional hospital areas of England and Wales. They are to be somewhat inelegantly known as Area Nurse-Training Committees, and each will have 15 members (16 or 17 in the metropolitan regions) representing various interests. Five will represent the General Nursing Council, one the Central Midwives Board, four the regional hospital board, and one (two or three in metropolitan areas) the teaching hospitals. In addition the Minister will appoint two people after consultation with the local health authorities, and two after consultation with the local education authorities and with such universities as he thinks fit. A certain specified proportion of all these people must be Stateregistered nurses. The work of the committees is to advise and assist all training institutions, and also, if asked to do so, the General Nursing Council, and to promote improvement and research into training methods. All this is giving effect to recommendations made in 1947 by the working party on nursing. 